\title{
Markers of oxidative and antioxidative activity in female dogs with mammary gland tumour with and without additional vitamin $E$ supplementation
}

\author{
Renata Stavinohová1, Jana Lorenzová ${ }^{1}$, Ivana Papežíková2, Ivana Borkovcová3, \\ Jakub Pfeifr ${ }^{1}$, Antonín Lojek $^{4}$, Markéta Mrázová1, Michal Crha ${ }^{1}$
}

\begin{abstract}
${ }^{1}$ University of Veterinary and Pharmaceutical Sciences Brno, Faculty of Veterinary Medicine, Department of Surgery and Orthopaedics, Dogs and Cats Clinic, Brno, Czech Republic

${ }^{2}$ University of Veterinary and Pharmaceutical Sciences Brno, Faculty of Veterinary Hygiene and Ecology, Department of Veterinary Ecology and Environment Protection, Brno, Czech Republic

${ }^{3}$ University of Veterinary and Pharmaceutical Sciences Brno, Faculty of Veterinary Hygiene and Ecology, Department of Milk Hygiene and Technology, Brno, Czech Republic

${ }^{4}$ Institute of Biophysics of the AS CR, v.v.i., Department of Free Radical Pathophysiology, Brno, Czech Republic
\end{abstract}

\section{Received January 17, 2012}

Accepted July 16, 2012

\begin{abstract}
The present study determined markers of oxidative and antioxidative activity in dog females affected with mammary gland tumour compared to healthy ones. The effect of additional vitamin $\mathrm{E}$ supplementation on oxidative and antioxidative status was evaluated as well. The study included 29 female dogs divided into 4 groups (groups 1 and 2 included females with a mammary gland tumour; groups 3 and 4 included healthy female dogs). Additional vitamin supplement containing $\alpha$-tocopherol was given to the females of groups 1 and 4. Dogs from groups 1 and 2 were anaesthetized before surgery (ovariohysterectomy and mastectomy); anaesthesia was used also in group 3, but without performeing surgery. The content of vitamin E (free $\alpha$-tocopherol), marker of antioxidative status, was measured in blood serum by liquid chromatography. The concentration of thiobarbituric acid reactive substances, marker of oxidative status, in serum and concentrations of protein and non-protein thiol groups, markers of oxidative and antioxidative status, in blood serum and in red blood cells were measured colorimetrically. In females with a mammary gland tumour from group 2, concentration of thiobarbituric acid reactive substances was significantly higher than 14 days after surgery and compared to healthy ones as well. In females with a mammary gland tumour from group 2, concentration of protein thiol groups in serum was significantly lower and concentration of non-protein thiol groups in serum was significantly higher than in healthy controls. The values of protein thiols in erythrocytes in females with mammary gland tumour from group 1 were significantly higher before supplementation with vitamin $\mathrm{E}$. The present study revealed that females with a mammary gland tumour were more burdened with oxidative stress compared to healthy dogs. The removal of the mammary gland tumour led to improvement of oxidative and antioxidative status. This is the first report focusing on the effect of additional $\alpha$-tocopherol supplementation on reducing oxidative stress by increasing antioxidative activity in females affected with mammary gland tumour; however, we did not prove it.
\end{abstract}

Mastectomy, ovariohysterectomy, $\alpha$-tocopherol, thiobarbituric acid reactive substances, protein and non-protein thiol groups

Reactive oxygen species (ROS) have many positive functions in the living organism (Badwey and Karnovsky 1980) but an uncontrolled increase of ROS can lead to oxidative damage and functional changes of proteins, lipids, nucleic acids and other biomolecules (Halliwell and Gutteridge 1985). There is evidence that ROS participate in cancer development (Portakal et al. 2000; Szczubial et al. 2004). Diplock (1991) agreed that low concentrations of essential antioxidants in blood circulation have been found to be associated with an increased risk of cancer. Oxidative stress (OS) is the result of imbalance between oxidative and antioxidative reactions leading to ROS excess (Si es 1993) and it is evaluated by the biomarkers of OS or activity of the antioxidative enzyme in plasma, red blood cells and tumour tissue (Portakal et al. 2000; McMichael 2007). Szczubial et al. (2004) measured concentrations of thiobarbituric acid reactive substances and total thiol 
groups in blood plasma and glutathione peroxidase and superoxide dismutase in erythrocytes of female dogs with a mammary gland tumour (MGT). Kumaraguruparan et al. (2005) revealed that lipid peroxidation increased in the MGT tissue of female dogs. Nowadays, administration of antioxidants to animals has become very popular. McMichael (2007) evaluated oxidative stress and using antioxidants in treatment and prevention of OS in dogs and cats. One of the studied antioxidants was vitamin E ( $\alpha$-tocopherol). Effects of vitamin E were studied also in humans and in laboratory animals (Brigelius et al. 2002; Shen et al. 2009). Shen et al. (2009) evaluated that vitamin E improved oxidative stress status and the metabolism of glucose and lipids. There are also other studies evaluating the effect of vitamin E supplemented to healthy dogs and dogs before and after exercises (Scott et al. 2001; Tran et al. 2007).

The aim of our study was to determine markers of oxidative and antioxidative activity in dog females affected with a mammary gland tumour compared to healthy ones. The effect of additional vitamin E supplementation on oxidative and antioxidative status was evaluated as well. We hypothesized that additional supplementation of vitamin E would reduce oxidative stress by increasing antioxidative activity in females affected with a mammary gland tumour.

\section{Materials and Methods}

Animal groups

The study included 29 female dogs which all were patients of the Department of Surgery and Orthopaedics, University of Veterinary and Pharmaceutical Sciences Brno. All dogs in the study underwent sampling and physical examination and were divided into 4 groups based on the mammary gland findings, vitamin $\mathrm{E}$ supplementation, surgery, and anaesthesia investigation. All females were starved before taking blood samples. Dogs with a clinically diagnosed mammary gland tumour underwent chest X rays as well.

Group 1 included four females, median age of 8 years, of different breeds, median weight of $22 \mathrm{~kg}$ with a clinically diagnosed MGT, but no other diseases; additional vitamin E was administered 10 days before the different extents of mastectomy and ovariohysterectomy. Group 2 included eight females, median age of 11.75 years, of different breeds, median weight of $8.95 \mathrm{~kg}$ with clinically diagnosed MGT, but no other diseases; additional vitamin $\mathrm{E}$ was not supplemented before the different extents of mastectomy and ovariohysterectomy. Control group 3 included six females, median age of 2 years, of different breeds, median weight of $22.5 \mathrm{~kg}$ with no MGT, no additional vitamin E supplementation, with anaesthesia conducted. Control group 4 included eleven females, median age of 3 years, of different breeds, median weight $26 \mathrm{~kg}$ without MGT, with additional vitamin E supplementation, without anaesthesia and surgery.

Females of all groups were fed different commercial diets, which according to the manufacturer contained the antioxidant vitamin E. Additional vitamin supplement, $\alpha$-tocopherol (E Hydrovit forte, $300 \mathrm{mg} / \mathrm{ml}$, Pharmagal, Nitra, Slovakia), was administered to females of groups 1 and 4 at the dose of $100 \mathrm{mg}$ per os once daily for 10 days.

\section{Anaesthesia}

Female dogs of groups 1, 2 and 3 were premedicated with butorphanol $0.2 \mathrm{mg} / \mathrm{kg}$ i.v. (Butomidor, Richter Pharma, Austria), medetomidine $0.01 \mathrm{mg} / \mathrm{kg}$ i.v. (Domitor, Orion Pharma, Finland) or midazolam i.v. (Dormicum, Roche Holding AG, Switzerland), propofol 1mg/kg i.v. (Propofol "Fresenius", Fresenius Kabi, Germany) was used for induction; general anaesthesia was maintained with isoflurane flow rate of $1.5 \%$.

Measurement of free $\alpha$-tocopherol, marker of antioxidative status

In group 1, free $\alpha$--tocopherol was measured 10 days prior to surgery (1A) and 10 days after supplementation with additional vitamin E few hours before surgery (1B). In group 2, free $\alpha$-tocopherol was measured 10 days prior to surgery (2A). In group 3, free $\alpha$-tocopherol was measured 10 days before anaesthesia (3A). Finally in group 4 , free $\alpha$-tocopherol was measured before supplementation with additional vitamin $\mathrm{E}$ (4A) and 10 days after supplementation (4B).

Free $\alpha$-tocopherol was extracted from blood serum into a non-polar solvent (n-hexane) by liquid/liquid technique, and determined by liquid chromatography method by Acquity UPLC liquid chromatograph (Waters, Milford, USA) with TUV detector (Citová et al. 2007).

Measurement of thiobarbituric acid reactive substances and protein and non-protein thiol groups

Concentration of thiobarbituric acid (TBA) reactive substances (syn. TBARS, TBARS/MDA-TBARS/ malondialdehyde) and protein and non-protein thiol groups (syn. sulphhydryl groups, thiols, SH groups), both markers of oxidative stress, were measured in group 1 ten days prior to surgery (1A), 10 days after additional 
supplementation with vitamin E few hours before surgery (1B) and 14 days after surgery (1D). In group 2, measurements were done 10 days prior to surgery (2A), under anaesthesia 10 min after surgery (2C) and 14 days after surgery (2D). In group 3, measurements were done 10 days before anaesthesia (3A) and 10 min after the start of inhalational anaesthesia (3C). In group 4, measurements were done before additional vitamin supplementation (4A) and 10 days after supplementation (4B).

Measurement of thiobarbituric acid reactive substances, marker of oxidative status

Concentration of TBARS, which reflected lipid peroxidation, was measured colorimetrically in blood serum. The absorbance of supernatant (butanol phase) was measured at $532 \mathrm{~nm}$ using the equipment Spectra Rainbow Thermo (Tecan, Switzerland) (Moore and Roberts 1998).

Measurement of protein and non-protein thiol groups, marker of oxidative and antioxidative status

Concentration of protein and non-protein SH groups was measured colorimetrically with modified Ellman method in blood serum and in erythrocytes (syn. RBCs, erys, haemolysates) (E1lman 1959). Briefly, $230 \mu 1$ of TRIS/EDTA buffer pH 8.2 with $100 \mu \mathrm{M}$ of dithionitrobenzoic acid (DTNB) were added to $20 \mu 1$ of sample or standard. After $30 \mathrm{~min}$, absorbance was measured at $412 \mathrm{~nm}$ against blank without DTNB. From the resulting value, non-protein thiols were subtracted to obtain protein thiols. Concentration of non-protein thiols was measured in a similar way. TRIS/EDTA buffer $\mathrm{pH} 8.9$ with $100 \mu \mathrm{M}$ of dithionitrobenzoic acid (DTNB) was used and absorbance at $412 \mathrm{~nm}$ was measured immediately after preparing reaction mixture. For both protein and non-protein thiols, L-cysteine was used as a standard. Protein concentration was measured with the use of BCA protein assay kit (Pierce, USA). Erythrocytes were centrifuged with $1 \mathrm{ml}$ of whole blood $\left(300 \mathrm{~g}, 4{ }^{\circ} \mathrm{C}, 10 \mathrm{~min}\right)$ and plasma discarded. To cellular mass, $1 \mathrm{ml}$ of cold distilled water was added and the cells were sonicated on ice for $45 \mathrm{~s}$. The lysates were centrifuged $\left(1000 \mathrm{~g}, 4^{\circ} \mathrm{C}, 10 \mathrm{~min}\right)$, supernatants were diluted 1:9 with cold distilled water and used for the measurement. For determination of non-protein thiols, samples were deproteinated with trichloroacetic acid. One hundred $\mu 1$ of sample were mixed with $50 \mu 1$ of $15 \%$ trichloroacetic acid and centrifuged $\left(20,000 \mathrm{~g}, 15 \mathrm{~min}, 4^{\circ} \mathrm{C}\right)$. Supernatants were used for the measurement.

\section{Statistical methods}

Regarding the character of data from the present study we used parametric tests (One-Way ANOVA, paired $t$-test, Tukey's test) and nonparametric tests (Kruskal-Wallis, Wilcoxon and Steel-Dwass test) for statistical analysis of the values. Results were considered significant at the significance level of $P \leq 0.05$ and high significance level of $P \leq 0.01$.

\section{Results}

Concentrations of vitamin $\mathrm{E}$ in blood serum of healthy female dogs and those affected with a mammary gland tumour are expressed as median \pm standard deviation. Vitamin $\mathrm{E}$ was $12.8 \pm 15.63 \mathrm{mg} / \mathrm{l}$ in female dogs 10 days before surgery, $17.9 \pm 22.39 \mathrm{mg} / \mathrm{l}$ in female dogs 10 days after vitamin E supplement (VS) few hours before surgery, $8.85 \pm 5.42 \mathrm{mg} / \mathrm{l}$ in female dogs 10 days before surgery, $9.9 \pm 6.19 \mathrm{mg} / \mathrm{l}$ in female dogs 10 days before anaesthesia, $6.5 \pm 7.86 \mathrm{mg} / \mathrm{l}$ in female dogs 10 days before VS and $6.5 \pm 5.96 \mathrm{mg} / 110$ days after VS. There was no significant difference in the concentrations of free $\alpha$-tocopherol among the individual groups.

Results of TBARS in serum, protein thiols in serum, protein thiols in RBCs, non-protein thiols in serum, and non-protein thiols in RBCs are presented in Table 1. Significant difference of $P \leq 0.05$ of TBARS in serum was found between groups $2 \mathrm{C}$ and $2 \mathrm{D}$ $(P=0.010), 2 \mathrm{~A}$ and $2 \mathrm{D}(P=0.013), 2 \mathrm{~A}$ and $3 \mathrm{~A}(P=0.032), 2 \mathrm{~A}$ and $4 \mathrm{~A}(P=0.019)$. Significant difference $(P \leq 0.01)$ of TBARS in serum was found between groups $2 \mathrm{C}$ and $3 \mathrm{C}$ $(P=0.003)$. Significant difference $P \leq 0.01$ of protein thiols in serum was found between groups $2 \mathrm{C}$ and $3 \mathrm{C}(P=0.008)$. Significant difference of $P \leq 0.05$ of protein thiols in RBCs was found between groups $1 \mathrm{~A}$ and $1 \mathrm{~B}(P=0.030)$. Significant difference of $P \leq 0.05$ of non-protein thiols in serum was found between groups $2 \mathrm{C}$ and $3 \mathrm{C}(P=0.033)$.

In females with a mammary gland tumour from group 2 , concentration of thiobarbituric acid reactive substances was significantly higher than 14 days after surgery and compared to healthy ones as well. In females with a mammary gland tumour from group 2, concentration of protein $\mathrm{SH}$ groups in serum was significantly lower and concentration of non-protein $\mathrm{SH}$ groups in serum was significantly higher than in healthy controls. The values of protein thiols in erythrocytes in females with a mammary gland tumour from group 1 were 
Table 1. Results of thiobarbituric acid substances, protein and non-protein thiol groups in healthy dog females and those affected with a mammary gland tumour (median \pm standard deviation)

\begin{tabular}{lcccccc}
\hline Group & $\begin{array}{c}\mathrm{n} \\
\text { females }\end{array}$ & $\begin{array}{c}\text { TBARS } \\
(\mu \mathrm{mol} / \mathrm{l}) \text { serum }\end{array}$ & $\begin{array}{c}\text { Protein SH } \\
\text { groups }(\mu \mathrm{mol} / \mathrm{l}) \\
\text { serum }\end{array}$ & $\begin{array}{c}\text { Protein SH groups } \\
(\mu \mathrm{mol} / \mathrm{l}) \mathrm{RBCs}\end{array}$ & $\begin{array}{c}\text { Non-protein SH } \\
\text { groups }(\mu \mathrm{mol} / \mathrm{l}) \\
\text { serum RBCs }\end{array}$ & $\begin{array}{c}\text { Non-protein SH } \\
\text { groups }(\mu \mathrm{mol} / \mathrm{l})\end{array}$ \\
\hline 1A & 4 & $1.62 \pm 0.46$ & $154 \pm 16.97$ & $141.5 \pm 51.69^{\mathrm{a}}$ & $7,6 \pm 4.02$ & $16 \pm 4.5$ \\
1B & 4 & $1.63 \pm 0.33$ & $168.5 \pm 20.11$ & $93.5 \pm 50.48^{\mathrm{a}}$ & $13 \pm 4.57$ & $17 \pm 6.5$ \\
1D & 4 & $1.42 \pm 0.44$ & $202 \pm 46.75$ & $59.5 \pm 59.28$ & $12.4 \pm 1.46$ & $24 \pm 5.97$ \\
2A & 8 & $2.47 \pm 1.2^{\mathrm{a}}$ & $124.5 \pm 53.90$ & $151.5 \pm 56.22$ & $9.15 \pm 4.95$ & $16 \pm 8.23$ \\
2C & 8 & $2.37 \pm 0.98^{\mathrm{a}, \mathrm{b}}$ & $117 \pm 32.51^{\mathrm{b}}$ & $94 \pm 20.05$ & $11.3 \pm 3.07^{\mathrm{a}}$ & $16 \pm 7.25$ \\
2D & 8 & $1.17 \pm 0.33^{\mathrm{a}}$ & $150.13 \pm 51.63$ & $118 \pm 30.10$ & $11.4 \pm 2.32$ & $17 \pm 4.68$ \\
3A & 6 & $1.41 \pm 0.34^{\mathrm{a}}$ & $194.5 \pm 69.79$ & $136 \pm 60.26$ & $10.65 \pm 2.59$ & $18.5 \pm 9.11$ \\
3C & 6 & $1.13 \pm 0.49^{\mathrm{b}}$ & $176 \pm 26.55^{\mathrm{b}}$ & $109 \pm 58.71$ & $6.7 \pm 4.05^{\mathrm{a}}$ & $18 \pm 6.71$ \\
4A & 11 & $1.5 \pm 0.46^{\mathrm{a}}$ & $185 \pm 73.71$ & $132 \pm 59.64$ & $9.2 \pm 9.10$ & $20 \pm 8.92$ \\
4B & 11 & $1.58 \pm 0.44$ & $239 \pm 60.20$ & $132 \pm 63.07$ & $9.8 \pm 5.0$ & $17 \pm 12.72$ \\
\hline
\end{tabular}

${ }^{\mathrm{a}}$ significant difference $P \leq 0.05$, ${ }^{\mathrm{b}}$ significant difference $P \leq 0.01$

TBARS - thiobarbituric acid substances, $\mathrm{SH}$ - sulphhydryl groups, RBCs - red blood cells

We compared TBARS and $\mathrm{SH}$ in the group between time periods (1A, 1B, 1D), (2A, 2C, 2D), (3A, 3C) and $(4 \mathrm{~A}, 4 \mathrm{~B})$ and vitamin $\mathrm{E}$ in $1 \mathrm{~A}, 1 \mathrm{~B}$ and $4 \mathrm{~A}, 4 \mathrm{~B}$. We compared TBARS and SH between groups in same time period (1A, 2A, 3A, 4A), (1B, 4B), (2C, 3C) and (1D, 2D) and vitamin E in 1A, 2A, 3A, 4A and 1B, 4B.

Time periods of collection of the samples: $1 \mathrm{~A}-10$ days before surgery, $1 \mathrm{~B}-10$ days after additional vitamin E supplement (AVS) few hours before surgery, 1D - 14 days after surgery, 2A - 10 days before surgery, 2C - under anaesthesia 10 minutes after surgery, 2D - 14 days after surgery, 3A - 10 days before anaesthesia, 3C 10 minutes after the start of inhalational anaesthesia, 4A - before AVS, 4B - 10 days after AVS.

significantly higher before supplementation with vitamin E. The present study revealed that females with a mammary gland tumour were more burdened with oxidative stress compared to healthy dogs. The removal of the mammary gland tumour led to improvement of oxidative and antioxidative status.

\section{Discussion}

In the present study, females of group 2 with MGT without vitamin E had higher TBARS values in serum under anaesthesia 10 min after mastectomy and ovariohysterectomy than 14 days after the surgery. Concentration of thiobarbituric acid substances in serum was also higher in females of group 2 with MGT without vitamin E 10 days before the surgery than 14 days after the surgery. The results revealed that MGT could have induced oxidative stress in females affected with MGT of group 2. Treatment of MGT by mastectomy led to improvement of oxidative and antioxidative status in females of group 2 fourteen days after surgery. The values of protein thiols in RBCs in females of group 1 with MGT were higher before supplementation with vitamin $\mathrm{E}$. We hypothesized that mammary gland tumour could have adequately increased protein thiols in RBCs in females of group 1 . This is the first study evaluating the changing levels of TBARS, protein and non-protein SH groups in the period before surgery, after surgery and during the postoperative period in female dogs with MGT.

Szczubial et al. (2004) measured levels of TBARS in plasma in female dogs with malignant and benign mammary tumours and in healthy female dogs before surgery with similar results. In our study, TBARS values in serum were higher in females of group 2 ten days before the surgery, than in healthy females of (control) group 3 ten days before anaesthesia. Concentration of thiobarbituric acid substances in serum 
were higher in dogs of group 2 ten days before the surgery than in healthy dogs of (control) group 4 prior to administration of vitamin E. From our results it can therefore be deduced that MGT could have participated in oxidative stress in females of group 2. Concentrations of thiobarbituric acid substances in serum were higher in females of group 2 under anaesthesia 10 min after surgery than in healthy anaesthetized dogs of (control) group 3. That implies that the MGT, surgery and anaesthesia could have participated in oxidative stress in females of group 2. However, the higher age of dogs of group 2 could have increased TBARS values as well. Ames $(2004 a, b)$ described that aging increased oxidative damage to proteins and lipid membranes in human. Karpenko et al. (2008) assumed that intensive aging started from the age of 7 in dogs of large breeds. Stowe et al. (2006) confirmed that aging, diet restriction and litters affect vitamin E but TRAP value (total antioxidative capacity) was unaffected by treatment, age, sex or litters in Labrador retriever.

Value of protein thiols in serum was lower in females of group 2 under anaesthesia 10 min after surgery than in healthy anaesthetized females of (control) group 3 . The results revealed that healthy females of group 3 had higher protein thiols values in serum. In the study of Szczubial et al. (2004) SH groups tended to be higher in healthy dogs. We hypothesized that reduction of protein thiol values in serum of females with MGT in the second group in our study might have been due to the higher rate of protein oxidation or increased uptake of antioxidants by tumourous tissues. Buzby et al. (1980) described that malignant cells could scavenge antioxidants from circulation for their supplement. The value of non-protein thiols in serum was higher in females of group 2 under anaesthesia $10 \mathrm{~min}$ after surgery than in healthy anaesthetized females of (control) group 3 . We hypothesized that the mammary gland tumour, surgery and anaesthesia could have adequately increased non-protein thiols in serum in females of group 2. As thiols can be oxidized by aging (Ying et al. 2007), it is possible that age difference between groups could have influenced results as well. A study by Shen et al. (2009) revealed that obesity in laboratory rats increased OS and decreased antioxidative activity. Dog females in our study did not suffer from obesity. To the authors' knowledge, the effect of breed, anaesthesia, mastectomy and ovariohysterectomy in dogs on the oxidative and antioxidative status has not been published yet.

We did not prove any effect of additional vitamin $\mathrm{E}$ on the markers of oxidative and antioxidative activity in healthy females and those affected with a mammary gland tumour. It could have been due to the big variability of the values of vitamin E measured in serum.

\section{Acknowledgement}

This study was supported by the Internal Grant Agency of the University of Veterinary and Pharmaceutical Sciences Brno 62 /2010/Faculty of Veterinary Medicine.

\section{References}

Ames BN 2004a: Delaying the mitochondrial decay of aging. Ann NY Acad Sci 1019: 406-411

Ames BN 2004b: A role for supplements in optimizing health: the metabolic tune-up. Arch Biochem Biophys 423: $227-234$

Badwey JA, Karnovsky ML 1980: Active oxygen species and the functions of phagocytic leukocytes. Ann Rev Biochem 49: 695-726

Brigelius FR, Kelly FJ, Salonen JT, Neuzil J, Zingg JM, Azzi A 2002: The Europen perspective on vitamin E: current knowledge and future research. Am J Clin Nutr 76: 703-716

Buzby GP, Mullen JL, Stein TP, Miller EE, Hobbs CL, Rosato EF 1980: Host-tumor interactions and nutrient supply. Cancer 45: 2940-2948

Citová I, Havlíková L, Urbánek L, Solichová D, Nováková L, Solich P 2007: Comparison of a novel ultraperformance liquid chromatographic method for determination of retinol and alpha-tocopherol in human serum with conventional HPLC using monolithic and particulate columns. Anal Bioanal Chem 388: 675-681

Diplock AT 1991: Antioxidant nutrients and disease prevention: an overview. Am J Clin Nutr 53: 189-193 
Ellman GL 1959: Tissue sulfhydryl groups. Arch Biochem Biophys 82: 70-77

Halliwell B, Gutteridge JM 1985: The importance of free radicals and catalytic metals irons in human diseases. Mol Aspects Med 8: 89-193

Karpenko LIu, Bakhta AA, Sukhovol'skii OK 2008: Age-related characteristics of antioxidant system in healthy dogs. Adv Gerontol 21: 49-52

Kumaraguruparan R, Balachandran C, Manohar BM, Nagini S 2005: Altered oxidant-antioxidant profile in canine mammary tumours. Vet Res Commun 29: 287-296

McMichael MA 2007: Oxidative stress, antioxidants and assessment of oxidative stress in dogs and cats. J Am Vet Med Assoc 231: 714-720

Moore K, Roberts LJ 2nd 1998: Measurement of lipid peroxidation. Free Radic Res 28: 659-671

Portakal O, Ozkawa O, Erden IM, Bozan B, Kosan M, Sayek I 2000: Coenzym Q 10 concentrations and antioxidant status in tissues of breast cancer patients. Clin Biochem 33: 279-284

Scott KC, Hill RC, Lewis DD, Boning AJ Jr, Sundstrom DA 2001: Effect of alpha-tocopheryl acetate supplementation on vitamin E concentrations in Greyhounds before and after a race. Am J Vet Res 62: 1118-1120

Shen X, Tang Q, Wu J, Feng Y, Huang J, Cai W 2009: Effect of vitamin E supplementation on oxidative stress in a rat model of diet-induced obesity. Int J Vitam Nutr Res 79: 255-263

Sies H 1993: Strategies of antioxidant defense. Eur J Biochem 215: 213-219

Stowe HD, Lawler DF, Kealy RD 2006: Antioxidant status of pair-fed labrador retrievers is affected by diet restriction and aging. J Nutr 136: 1844-1848

Szczubial M, Kankofer M, Lopuszynski W, Dabrowski R, Lipko J 2004: Oxidative stress parameters in bitches with mammary gland tumours. J Vet Med A Physiol Pathol Clin Med 51: 336-340

Tran JL, Horvath C, Krammer S, Höller U, Zentek J 2007: Blood vitamin concentrations in privately owned dogs fed non-standardized commercial diets and after intake of diets with specified vitamin concentrations. J Anim Physiol Anim Nutr 91: 40-47

Ying J, Clavreul N, Sethuraman M, Adachi T, Cohen RA 2007: Thiol oxidation in signaling and response to stress: detection and quantification of physiological and pathophysiological thiol modifications. Free Radic Biol Med 43: $1099-1108$ 